\title{
Consultant Editor's Note regarding publication of a duplicate article: "Correlation between serum-ascites albumin concentration gradient and endoscopic parameters of portal hypertension (PMID: 16449830; Oct- Dec 2005)"
}

$\mathrm{D}$ ear Readers,

An Email was received from eTBLAST, a webbased search engine currently funded by National Institute ofHealth(NIH), in the US on 9/September/2008, regarding a manuscript published in the Kathmandu University Medical Journal (KUMJ) Vol. 3, No. 4, Issue 12. The title of the article was "Correlation between serum-ascites albumin concentration gradient and endoscopic parameters of portal hypertension (PMID: 16449830; Oct-Dec 2005)". They found that a similar article had been published in 1998 in American Journal of Gastroenterology. The title of that article was "Correlation between serum-ascites albumin concentration gradient and endoscopic parameters of portal hypertension (PMID: 9820392; Nov 1998)".

It seemed clear after going through both the articles that the composition in former one (PMID: 16449830), including the title, wording, graphs and even various references were literally copied $(>87.5 \%)$.

We take these kinds of events as a case of plagiarism and KUMJ Editorial Board has decided to duly retract the aforementioned article from KUMJ. Necessary procedures have already been taken to retract the article from NLM's PubMed and other indices that KUMJ is affiliated to.

An emergency meeting of the Editorial Board was called and the following decision were made regarding the matter:

1. The Editorial Board of KUMJ strongly condemns such a grave misconduct of publication ethics by such qualified doctors.

2. The article should be retracted both from Kathmandu University Medical Journal and NLM's PubMed.
3. All the authors viz. Principle author (Dr. Dipesh Lal Gurubacharya), Co-authors (Prof. Mathura KC, Prof. D. B. Karki) should be banned from publishing any article or material in KUMJ for one year (4 issues) starting from issue 24 .

4. All Medical Journals published in Nepal should be informed regarding the duplicate publication and the decision taken.

5. Nepal Medical Council (NMC), a body which grants license to the medical doctors should be informed about the duplicate publication and the decision taken by the Editorial Board of KUMJ.

6. The Medical College to which the authors are affiliated should be informed for necessary action.

7. The Editorial Board also decided to send a letter of apology to American Journal of Gastronenterology and through them also to the authors involved in writing of the original article (PMID: 9820392).

8. It was also decided that the authors of the duplicate article will be asked to reimburse a sum of Nepalese Rupees 2000.00 (Rs. Two thousand) for the cost incurred while publishing the duplicate article.

All authors are strongly notified that no references should be quoted from the above mentioned retracted article.

These actions have been taken as per the guidelines of Committee on Publication Ethics (COPE) and International Committee of Medical Journal Editors (ICMJE) as well as World Association of Medical Editors (WAME).

KUMJ always advocates following good publication ethics while writing scientific articles. 